\title{
THE STRESS DISTRIBUTIONS IN SHOULDERED SHAFTS UNDER AXISYMMETRIC LOADING
}

\section{E. GOOYER Eindhoven University of Technology, The Netherlands*}

\section{J. L. OVERBEEKE Eindhoven University of Technology, The Netherlands}

\begin{abstract}
The stress distributions in shouldered shafts in tension and in torsion were calculated by the finite element method (FEM) for notch radii that are of technical interest.

The calculated stress concentration factors $K$, and relative stress gradients normal to the surface were compared with values given in a well-known handbook used by many designers, and with literature, respectively. From this comparison it appears that :

- $K_{\mathrm{t}}$ values for a shouldered shaft in tension are up to 30 percent higher than the values given in mentioned handbook;

- the relative stress gradients can, within the range of notch radii $r$ that was investigated, be approximated by $2 / r$ for the tension case and $1 / r$ for the case of torsion.
\end{abstract}

Publication of reliable results from FEM calculations of stress concentrations are recommended in order to improve or extend the usability of the design data which are now available.

\section{INTRODUCTION}

For the assessment of the fatigue strength of shouldered shafts use is made on the one hand of the stress concentration factors (scf) to calculate the maximum elastic stress ranges, and on the other hand of the stress gradients in order to allow for the notch sensitivity of the real material.

The scf for shouldered shafts, as given in handbook (1) $\dagger$, that is used throughout in design offices, are:

- for torsional loading based on calculations (2):

- for loading in tension based on an extrapolation from the scf for shouldered flat bars, which, in turn, were determined mainly from photo-elastic tests carried out by several authors.

For the stress gradients it is usual to rely upon those given in (3). However, the values given in (3) are for shafts with deep hyperbolic notches.

Therefore, as a part of an investigation into the effect of nitrided surface layers on the fatigue strength of shafts, calculations by the finite element method (FEM) were carried through in order to determine the stress distributions in shouldered shafts loaded in tension or in torsion. Our analysis of the tensile case showed rather large differences in scf as compared to those from (1). Therefore, the stress distributions for shouldered flat bars in tension from which the latter ones were derived were calculated as a check.

The numerical calculations were carried out, see Fig. 1, for a shaft diameter $d=7.5 \mathrm{~mm}$, a shoulder ratio $D /$ $d=1.60$, and notch acuity ratios $r / d=0.133,0.05$, and

The MS. of this paper was received at the Institution on $21 \mathrm{July} 1989$ and accepted for publication on II February 1991

- Now at Fokker Aircraft, Amsterdam

+ References are given in the Appendix.
0.02 , respectively, where $r$ is the notch radius. These ratios were chosen because of their technical interest.

A summary of the results obtained is given below.

\section{ACCURACY, MESH SIZE, AND SPECIMEN LENGTH}

As the accuracy of calculations by FE methods cannot be predicted in advance, the required mesh sizes were determined as follows.

Starting with one or two elements, the von Mises stress concentration factors $K_{i}^{\prime}$ for shouldered shafts in tension were calculated for meshes having an increasing number of equal elements extending along the notch radius.

When the difference in $K_{1}^{\prime}$ obtained from two successive calculations had reduced to less than 2 percent, the higher number of elements was used for further cal-

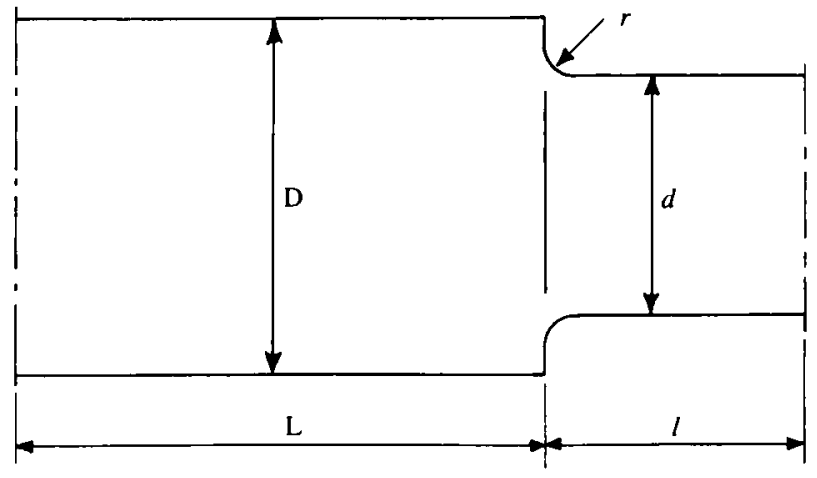

Fig. 1. Dimensions of the shouldered shafts and bars $d=7.5 \mathrm{~mm}$, $D / d=1.6 ; r / d=0.133,0.05$, and 0.02 


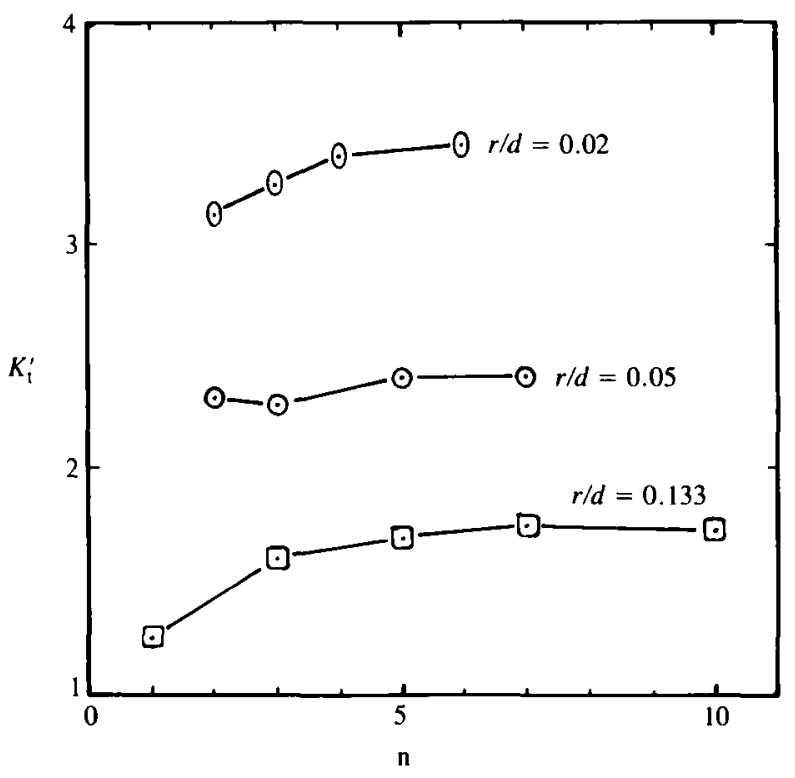

Fig. 2. Influence of the number of elements, $n$, extending along the notch radius, on $K$, for a shouldered shaft in tension

culations, provided that the gradients in the neck had a smooth appearance.

The results, plotted in Fig. 2, show that 10, 7, and 6 elements along the radius are sufficient for $r / d=0.133$, 0.05 and 0.02 , respectively.

The relative length $l / d$ of the shaft was fixed at $l / d=1.0$ and that of the shouldered part at $L / D=1.25$ after it was established that larger ratios did not change the results by more than 1 percent.

The overall accuracy of the scf obtained is, therefore, estimated to be equal to or better than 3 percent.

\section{SOFTWARE AND ELEMENTS USED}

It should be mentioned that for the above described screening, use was made of the FE-program IDEAS together with element 82 -an axisymmetric parabolic triangle having 6 nodes.

Tension was introduced by a fixed axial displacement between the end sections of the specimens. Similarly, a fixed rotation was used to introduce torsion.

For the final calculations the program MARC was used for logistic reasons. The elements used were parabolic quadrilateral elements, viz no. 62 for the axisymmetric cases and no. 26 for the case of plane stress. It follows that the accuracies obtained are at least as good as for the calculations with IDEAS.

\section{RESULTS}

The stress concentration factors, $K_{t}$, and the relative stress gradients $\chi$ when $x \rightarrow 0$, that is near the surface, see Fig. 3,

$$
\chi=-\frac{\mathrm{d} S_{1} / \mathrm{d} x}{S_{1 \max }} \text { (tension); } \chi=-\frac{\mathrm{d} T_{i} / \mathrm{d} x}{T_{\mathrm{tmax}}} \text { (torsion) }
$$

(where $S_{1}$ is the principal normal stress and $T_{1}$ is the tangential shear stress), are given in Table 1 together with those from (1) and (3), respectively.

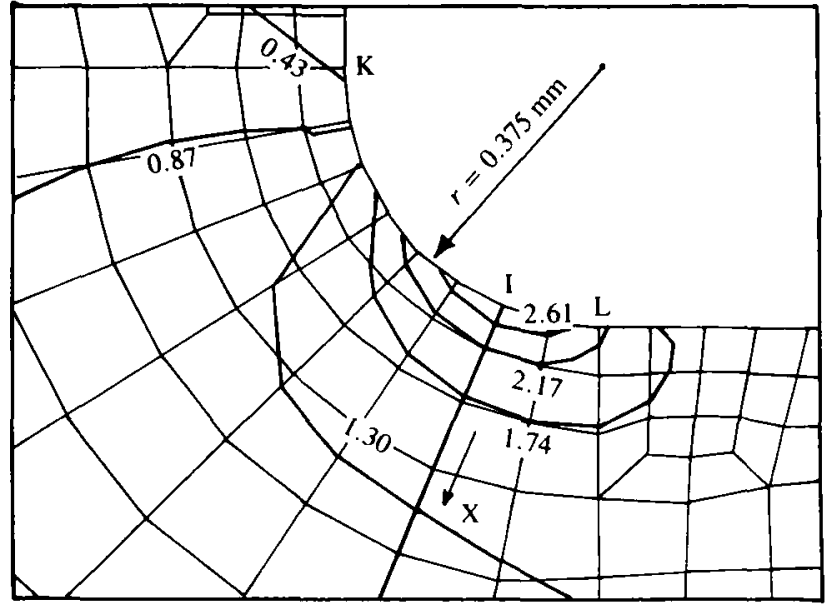

(a)

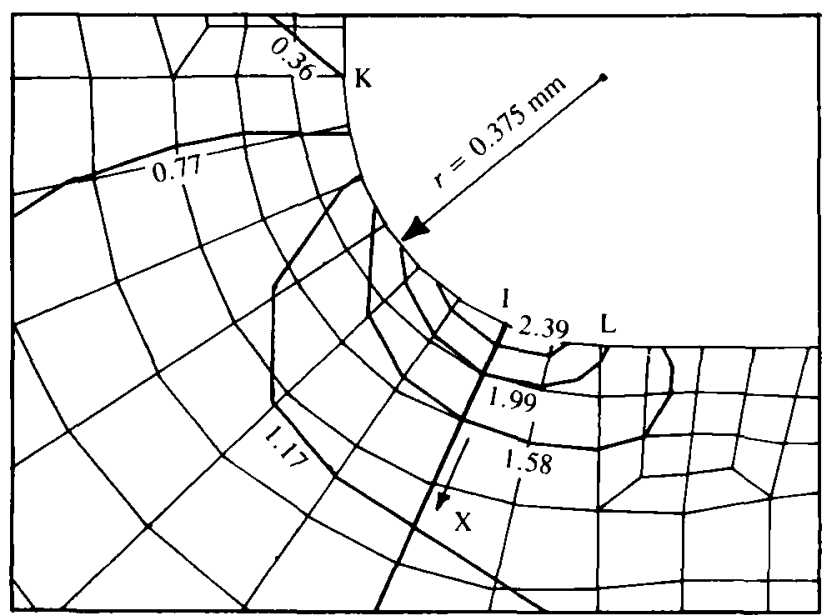

(b)

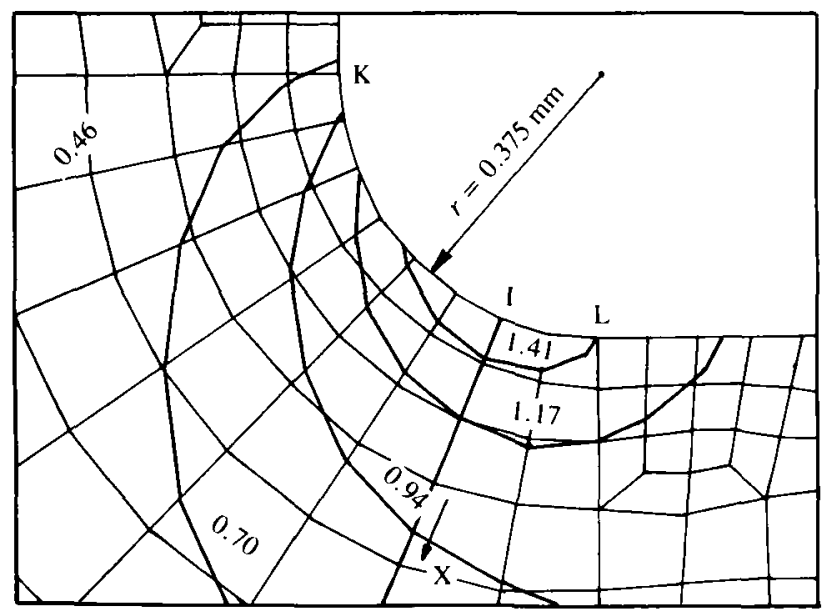

(c)

Fig. 3 Mesh pattern and lines of constant normalized maximum stress, $r / d=0.05$.
(a) shouldered bar in tension
(b) shouldered shaft in tension
(c) shouldered shaft in torsion

The comparisons given below are with regard to values from (1) or (3).

For obvious reasons the shouldered flat bar is treated first.

JOURNAL OF STRAIN ANALYSIS VOL 26 NO 3 1991 IMechE 
Table 1. Stress concentration factors $K_{\mathrm{t}}$ and stress gradients $\chi$ for $d=7.5 \mathrm{~mm}$ and $D / d=1.6$

\begin{tabular}{|c|c|c|c|c|}
\hline \multicolumn{5}{|c|}{ (a) Shouldered bar in tension } \\
\hline \multicolumn{2}{|c|}{$r / d$} & 0.133 & 0.05 & 0.02 \\
\hline \multirow[t]{2}{*}{$K_{1}$} & here & 2.16 & 3.04 & 4.37 \\
\hline & (1) & 2.10 & 2.88 & - \\
\hline$\chi$ & here & -1.8 & -4.9 & -12 \\
\hline $\mathrm{mm}^{-}$ & (3) & -2.0 & -5.3 & -13.3 \\
\hline
\end{tabular}

(b) Shouldered shaft in tension

\begin{tabular}{|c|c|c|c|c|}
\hline \multicolumn{2}{|c|}{$r / d$} & 0.133 & 0.05 & 0.02 \\
\hline$K_{\mathrm{t}}$ & here & 1.97 & 2.80 & 4.00 \\
\hline & (1) & 1.75 & 2.32 & 3.10 \\
\hline$\chi$ & here & -1.8 & -5.1 & -12 \\
\hline $\mathrm{mm}^{-1}$ & (3) & -2.0 & -5.4 & -13.3 \\
\hline
\end{tabular}

(c) Shouldered shaft in torsion

\begin{tabular}{ccccc}
\hline & & 0.133 & 0.05 & 0.02 \\
\hline$K_{1}$ & here & 1.31 & 1.64 & 2.13 \\
& $(\mathbf{1})$ & 1.31 & 1.62 & - \\
$\chi$ & here & -1.0 & -2.3 & -5.7 \\
$\mathrm{~mm}^{-1}$ & $(\mathbf{3})$ & -1.3 & -2.9 & -6.9 \\
\hline
\end{tabular}

\subsection{Shouldered bars in tension}

The scf calculated here are 3 percent higher for $r /$ $d=0.133$ and 6 percent for $r / d=0.05$, indicating a systematically increasing difference for a decreasing radius. The calculated stress gradients $\chi$ are about 10 percent lower.

\subsection{Shouldered shafts in tension}

The calculated scf are up to about 30 percent higher. It follows that the extrapolation from a flat bar as used in (1) severely underestimates the scf. However, the errors in scf for the flat bar are of influence too. From our results it follows that the scf for a shouldered shaft is 92 percent of that for a shouldered bar. Whether this is also true in the case of bending is not known, but probable.

The calculated stress gradients $\chi$ are again about 10 percent lower.

However, it should be noted that for the smaller radii the values of $\chi$ for a shaft and a bar are virtually the same.

\subsection{Shouldered shaft in torsion}

The calculated scf $K_{t}$ for the tangential shear stresses $T_{t}$ are within 1 percent of the analytic values quoted in (1).

However, the stress gradients $\chi$ of those shear stresses are 20-30 percent lower than those according to (3).

\subsection{Stress fields}

The stress fields for $r / d=0.05$ are given in Fig. 3 together with the mesh used in this case.

Figures 3(a) and (b) show lines of normalized maximum principal stresses for tension $S_{1} / S$ and Fig. 3(c) shows lines of normalized maximum tangential shear stresses for torsion $T / T$.

Figure 4 shows their variations along the surface of the notch, and Fig. 5 shows their decrease normal to the surface near the place of maximum stress, $I$, (see Fig. 3).

From these figures the similarity of the stress fields for tension loading is very clear.

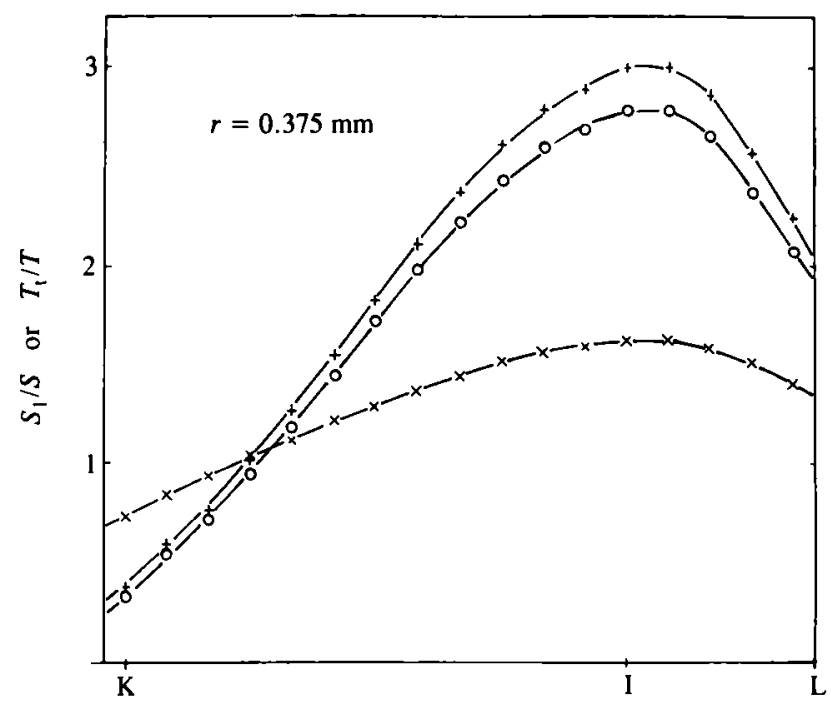

Fig. 4. Variation of $S_{1} / S$ or $T_{V} / T$ along the surface, (see also Fig. 3), $r / d=0.05$

$$
\begin{aligned}
& + \text { bar in tension } \\
& \times \text { shaft in tension } \\
& \times \text { shaft in torsion }
\end{aligned}
$$

\section{DISCUSSION}

From the above it follows that the scf for shouldered shafts in tension are $20-30$ percent higher than the ones given in (1). So these latter ones are essentially too unconservative to be used in fatigue strength calculations.

However, one may assume that they have been used by designers for several decennia.

In general the stress gradients $\chi$ for tension are about 10 percent and for torsion about 20 percent lower than the ones which follow from (3).

However, the allowance for the notch sensitivity of the material (that is the derivation of the fatigue notch factor

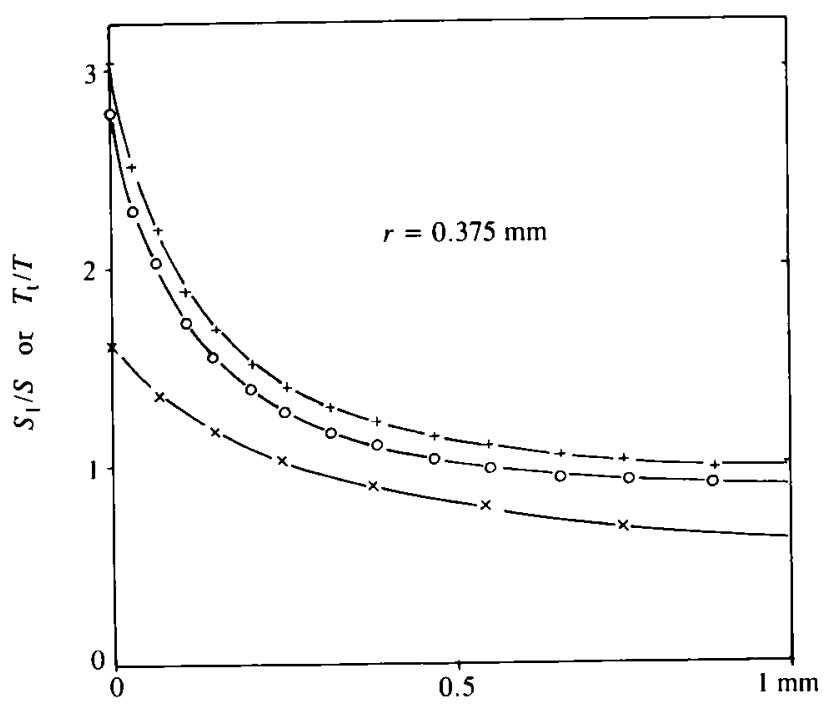

Fig. 5. Variation of $S_{1} / S$ or $T / T$ in $x$ direction, (see also Fig. 3), $r / d=0.05$

$$
\begin{aligned}
& + \text { shaft in tension } \\
& + \text { shaft in tension } \\
& \times \text { shaft in torsion }
\end{aligned}
$$


$K_{\mathrm{f}}$ from the scf $K_{\mathrm{t}}$ ) is very seldom more than 30 percent. So when the stress gradient is used as a parameter for this derivation, a 20 percent error in $\chi$ will result in an error in $K_{\mathrm{f}}$ of less than, say, 5 percent.

A possible error of this size is negligible as compared to the uncertainties about the fatigue characteristics of the material.

From the above and Table 1 it follows also that the often used approximations

$$
\begin{aligned}
& \chi=2 / r \text { for tension } \\
& \chi=1 / r \text { for torsion }
\end{aligned}
$$

have sufficient accuracy in this respect.

\section{CONCLUSIONS AND RECOMMENDATIONS}

From an analysis by finite element method of the stress distributions in shouldered shafts loaded in tension or in torsion, the stress concentration factors $K_{\mathrm{t}}$ were determined.

A comparison of the results of this analysis and the scf given in a well-known handbook (1) reveals that

- the scf for torsion are about equal;

- the scf for tension are up to 30 percent higher than those given in (1).

This underestimation in (1) is only partly due to an underestimation of the scf for a shouldered flat bar from which they were derived and it is anticipated that for bending similar discrepancies in scf will exist.

It follows that fatigue strength calculations of shouldered shafts in tension (and probably also in bending) based on (1) are rather unconservative.

The relative stress gradients $\chi$ normal to the surface, often used as a parameter to estimate the fatigue notch factor $K_{\mathrm{f}}$, can be approximated with sufficient accuracy to $2 / r$ in the case of tension and $1 / r$ in the case of torsion.

On the one hand FEM-calculations are used throughout in design offices for the stress analysis of (complex) structural parts, while on the other hand they are seldom used to check known design data, although, in a number of cases, these are known to be derived from approximations or extrapolations.

Therefore, the authors recommend that the results of reliable FEM-calculations covering one or more geometrical configurations dealt with in (1) or extending the potentials of (1), should be published in order to improve the accuracy and/or the amount of basic design data.

\section{APPENDIX}

REFERENCES

(1) PETERSON, R. E., Stress concentration factors, 1974 (John Wiley and Sons, New York).

(2) MATTHEWS, G. J. and HOOK, C. J., 'Solutions of axisymmetric torsion problems by point matching', J. of Strain Analysis, 1971, 6, 124-133.

(3) LEVEN, M. M., Stress gradients in grooved bars and shafts, Proc SESA, 1955, 13, 207. 